yourself' afficionado there are also the complete measles virus antigenome and its protein consensus sequences.

The chapters are generally well-written in an easily understandable fashion. The information is relatively up-to-date with 1992, 1993 and occasional 1994 references. This book provides an interesting and useful reference text on measles virus.

\section{A. HART}

\section{Principles and Practice of Clinical Virology, 3rd edition}

J. K. ZUCKERMAN. 1995. ISBN 0-471-931-063. John Wiley and Sons, New York. Pp. 778. $£ 79.95$

This welcome third edition of an excellent virology text is suitable as a reference work for undergraduates, a bedrock text for trainees in medical virology and a valued companion to professional virologists. One of its particularly admirable qualities is a style which is generally clear and easy to read.

The new chapter on herpes simplex expands molecular aspects of virus replication and diagnosis; the section on management has also been extended and brought up to date. The chapter on varicella has been improved by the introduction of clearer diagrams, a more detailed description of the virus genomic organisation, and a longer, but still rather brief, description of varicella and zoster treatment. The new chapter on cytomegalovirus maintains the previous high standard; however, there is no description of the new leucocyte antigen detection test, which is favourably compared with other diagnostic techniques but not described.

The chapter on human herpesviruses (HHV) 6 and 7 has been extended to reflect current increased knowledge and understanding of the biology and clinical manifestations of HHV6. A new section describing the discovery of, and what little is known about, HHV7 is a welcome addition and the brief section about the relationship between the two viruses (or is it three?) offers the reader an opportunity to speculate what the next edition of the book might include about these interesting viruses. However, the book is not without a few weaknesses. I was disappointed to see the continued adjunct of a section on classification and taxonomy of herpesviridae at the beginning; in my view this should form an appendix. To the casual browser these first few pages give an entirely false impression of the book's scope.

The chapter on hepatitis viruses has been restored and the subdivision of the second edition reversed. I expect that in future there will be a need to devote a full chapter to each of the hepatitis viruses (except possibly, delta), and the editors may wish to consider recruitment of additional authors for this. In my view, to give adequate consideration to such a varied group of viruses within a single chapter of a book at this level is not achievable.

The book has a substantial market in the UK, and the discussion of measles and mumps would be improved if space was devoted to European, and particularly UK, immunisation strategies, instead of only describing immunisation strategies in the USA and third world. On a more positive note, the new chapter on rubella includes more about the molecular organisation of the virus and an up-date on prenatal diagnostic strategies. Omission of the illustration of the single radial haemolysis test perhaps marks the passing of an era as this test follows haemagglutination inhibition into the history books.

Separation of the different virus families within the 'arbovirus' ecological category is a considerable improvement, making the subject much easier for the student to understand and providing a 'user friendly' reference work for the virologist who temporarily forgets whether or not Igbo Ora Virus is part of the Bunyaviridae! Similarly, the separation of VHF agents into their properly separate chapters enables the authors to give a more complete description of these exotic and fascinating viruses and the diseases they cause.

The chapter on human papovaviruses has been happily divided into two, a recognition of the importance of both papilloma and polyoma viruses. The chapter on human retroviruses has been expanded and includes more on both molecular biology and therapeutics. The chapter on human prion disease has been amended to accommodate recent advances and the case histories, which were somewhat out of place in earlier editions, have been omitted.

Overall, the changes introduced in this third edition are improvements; the book has evolved from its beginnings and is better for it. The authors and editors have produced a new and valuable text which those who have the earlier editions will probably wish to acquire. The authors will no doubt be dismayed to reflect that in a few years a new edition will be required to accommodate increasing knowledge in the rapidly changing and exciting field of clinical virology. They may be consoled by the recognition that Principles and Practice of Clinical Virology has firmly established itself as a robust and important text, well able to develop along with the subject.

D. WESTMORELAND 